\title{
Model of Independent Intervention Program for Improving Social Skills of Children with Autism Spectrum Disorder
}

\author{
Rudi Susilana ${ }^{a}$, Herlina $^{b}$ \\ Universitas Pendidikan Indonesia, \\ Bandung 40154, West Java, Indonesia \\ Correspondinge-mail: ${ }^{a}$ rudi_susilana@upi.edu, ${ }^{b}$ herlinahasan_psi@upi.edu
}

\begin{abstract}
The number of children with autism has drastically increased, despite the treatment being inadequate. The complexity of treatment for children with autism is due to special approach, method, and experts needed, as well as being relatively longterm and expensive. This present research obtained model of independent intervention program for children with autism through the development of systematic review result towards a number of empirical articles on autism intervention programs involving parents. The development of the model is based on cross-field study involving curriculum development, psychology (in particular, psychology of special needs children), and adult education (andragogy). The model proposed and developed in this research is expected to give parents of children with autism a solution to be able to independently perform intervention and early treatment for their children. By the intervention of their parents, the social skills of the children can be improved. Furthermore, the model is assumed to be effective, for parents are the closest figure to their children and able to spend longer time to guide them. Moreover, parents are assumed to be financially capable in performing the treatment as the cost of the intervention can be reduced due to its independent aspect.
\end{abstract}

Keywords: $\quad$ children with autism spectrum disorder independent intervention, parents, social skills

\section{INTRODUCTION}

Based on the results of studies conducted in the late 60 s and early $70 \mathrm{~s}$, globally speaking, there has been an increase in the prevalence of people with Autism Spectrum Disorder (ASD), 20-30 times greater (CDC, 2014). This condition has prompted a number of parties to show some effort in performing intervention. The intervention towards people with ASD should be performed correctly, as early and as intensive as possible, thus enabling people with ASD to improve the quality of their behavior and weaknesses (Stone \& DiGeromino, 2014).

Several studies show that the therapy for people with ASD costs highly and requires long term, impeding parents of children with ASM in performing intervention (Jarbrink, et al., 2006; Wang, et al., 2013; Poling and Edwards, 2014); Kaiser \& Hancock, 2003; Krasny et al., 2003; Leef, 2005; McConachie \& Diggle, 2007; Rocha, et al, 2007; White et al., 2007; Koenig et al., 2009; Matson, et al., 2009; Schreiber, 2010). In addition to this, the demand on the implementation of intensive intervention has been considered unrealistic, for it is time-consuming, making it difficult for parents to focus on other daily activities (Harris, t.t.).

As a solution, it is recommended to perform empowerment for parents as the intervener for children with ASD. The solution is expected to make the intervention more cost-efficient and more realistic to implement. The empowerment for parents as the intervener is seen as an important factor for the effectivity of treatment for children with ASD since parents are able to actively participate in the whole process of intervention, as well as understanding their key role in the ongoing intervention (Dept. Of Health NYS, 2002; Dept. for Education UK, 2011; Lowry, 2011; Elder, 2013; Moroz, 2015), and the generalization of children's skills (Steiner, et al., 2012; Elder, 2013). The empowerment also leads to better prognosis and life quality for the long term (Elder, 32013). Another positive point obtained from the empowerment for parents as the intervener is better welfare (in particular, physically and emotionally) for parents and other family members involved (Rogers, 2000; Schertz and Odom, 2007; Schreiber, 2010).

\section{METHODOLOY}

The present training model investigated is the result of the development of literature review performed to get a picture of empowerment towards parents as the intervener towards children with Autism Spectrum Disorder (ASD). Systematic review has been done on a number of articles with criteria as follows: (1) The article is a primary report of study result on the intervention towards children with ASD involving parents; (2) The article includes an idea on intervention program as a whole, allowing for the analysis of the program structure; (3) The article is published in a journal accessible through internet; and (4) The article is the result of the recent study, published between 2014-2016. 
Based on the criteria elaborated, there are six articles chosen as follows:

a. Study result of Shire et al's, elaborated in "Parent's adoption of social communication intervention strategies: Families including children with Autism Spectrum Disorder who are minimally verbal" as published in J Autism Dev disorder, June 2015, 45(6):1712-1724.

b. Study result of Thomson \& Jenkins's (2016), elaborated in "Training parents to promote communication and social behavior in children with Autism: The Son-Rise Program" as published in Commun Disord Deaf Stud Hearing Aids, 2016, 4:1, 1-7.

c. Study result of Pickard et al's, elaborated in "A mixed-method evaluation of the feasibility and acceptability of a telehealth-based parentmediated intervention for children with autism spectrum disorder" as published in Autism, 20(7), 845-855.

d. Study result of Bearss et al's, elaborated in "Effect of parent training vs parent education on behavioral problems in children with autism spectrum disorder, a randomized clinical trial" as published in Jama, 2015, 313(15), 1524-1533.

e. Study result of Brian et al's, elaborated in "The Social ABCs caregiver-mediated intervention for toddles with autism spectrum disorder: Feasibility, acceptability, and evidence of promise from a multisite study" as published in Autism Research, 9:899-912.

f. Study result of Tonge et al's, elaborated in "A randomized group comparison controlled trial of preschoolers with autism: A parent education and skills training intervention for young children with autistic disorder" as published in Autism, 2014, vol. 18(2), 166-177.

\section{RESULTS AND DISCUSSION}

\subsection{The Results of Systematic Review}

The results of the review on the six selected studies concludes that the intervention program for people with ASD involving parents is structured as follows: (1) the main goal of the program is specifically to develop children's particular skill(s); (2) Program materials are adjusted in accordance to the main goal (skills expected to be mastered by the children); (3) In general, the method begins with workshop for parents, either as theory or intervention practice, followed by the implementation of intervention towards the children; and (4) The evaluation is performed on both parents and children by experts and/or parents. The evaluation may be done before, during, or a couple weeks or months after the training or intervention.

\subsection{The Model of Independent Intervention Program}

Referring to the conclusion of study results reviewed above, an intervention model entitled Independent Intervention Program (Program Intervensi Mandiri or PIM) has been developed. The program is directed towards parents in order to be able to design and perform intervention towards their children with ASD, so that the social skills of the children can be improved. The social skills are basic skills needed by someone to be able to interact with others.

In general, PIM has similar structure to the structure of the existing intervention program involving parents. However, there are several main differences unique to this intervention program, such as the goal to promote independence within parents in designing and implementing the individual intervention program towards their children, especially intervention program intended to improve the social skills of children with ASD.

The model of PIM can be illustrated as follows:

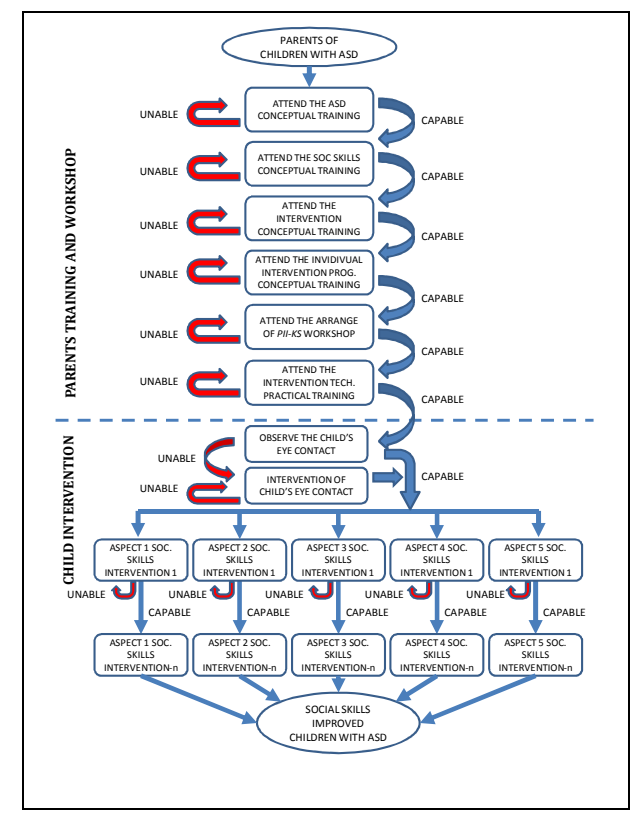

Fig.1. Model of Independent Intervention Program (Program Intervensi Mandiri)

The model of Program Intervensi Mandiri (PIM) is organized in two related main activities elaborated as follows:

A. Training program.

Training is given to parents of children with ASD, expecting them to be capable in:

- Independently designing individual intervention program regarding the social skills of children with ASD.

- Performing intervention of social skills towards children with ASD. 
The training contents include conceptual materials (basic information on ASD, social skills, intervention, and individual intervention program) and practical materials (information regarding techniques on organizing individual intervention program and intervention techniques). The training is done before parents perform intervention towards their children.

B. Intervention program.

This activity is an intervention practice implemented by parents towards children with ASD, referring to the individual intervention program for social skills (Program Intervensi Individual Keterampilan Sosial or PII-KS) organized. This program aims at improving children's social skills.

The intervention program contents include intervention towards children's social skills, as highlighted by The National Autistic Society (2014).

Intervention is performed only when parents' capability have been considered adequate during the training session.

\section{CONCLUSION}

The model of independent intervention program (Model Program Intervensi Mandiri or PIM) is a model developed from a number of intervention programs for children with ASD which involve parents. The model proposed in the present research is expected to reduce parents' dependence of professional therapist in performing the intervention. Besides nurturing independence and confidence within the parents, the cost of intervention can be reduced. Furthermore, there would be more time allocated for the intervention, thus allowing parents and children to interact more intensively. However, this does not merely ignore the role of experts (e.g., psychologist) and therapist. It should be noted that parents should seek advice from the experts in performing more valid and effective intervention.

\section{REFERENCES}

[1] Bearss, K. et al. . (2015) Effect of parent training vs parent education on behavioral problems in children with autism spectrum disorder, a randomized clinical trial. Jama, , 313, 15, pp. 1524-1533.

[2] Brian, J.A., et al. (2016) The Social ABCs caregiver-mediated intervention for toddles with autism spectrum disorder: Feasibility, acceptability, and evidence of promis from a multisite study. Autism Research, , 9, 899912
[3] CDC. Prevalence of Autism Spectrum Disorder Among Children Aged 8 Years Autism and Developmental Disabilities Monitoring Network, 11 Sites, United States, 2010. Morbidity and Mortality Week Report, Surveillance Summaries, March 28, 2014, 63(2): 1-21

[4] Department for Education UK. Support and aspiration: A new approach to special educational needs and disability, $A$ consultation, vol 8027, 2011. The Stationery Office.

[5] Department of Health New York State. Chapter IV - Intervention Methods for Young Children with Autism, 2002, Retrieved from: https://www.health.ny.gov/community/infant s_children/early_intervention/disorders/autis m/ch4_pt1.htm (9 Desember 2014)

[6] Elder, J. (2013), Empowering Families in the Treatment of Autism, in Fitzerald, M (ed.) Recent Advances in Autism Spectrum Disorder,. 1.

[7] Harris, S. (n.d.). Family issues. Maryland: Autism Society. Retrieved from: http://www.autism-society.org/living-withautism/family-issues/ (2 December 2014)

[8] Jarbrink, K. et al. (2007), Cost-impact of young adults with high-functioning autistic spectrum disorder. Research In Developmental Disabilities, 28, 1, pp. 94104.

[9] Kaiser, A.P., \& Hancock, T.B. (2003), Teaching parents new skills to support their young children's development. Infants and Young Children, 16, 1, pp. 9-21

[10] Koenig, K. et al. (2009), Group intervention to promote social skills in school-age children with pervasive developmental disorders: Reconsidering efficacy. Journal of Autism and Developmental Disorders, 39, 8, pp. 1163-1172.

[11]Krasny, L. et al. (2003), Social skills interventions for the autism spectrum: Essential ingredients and a model curriculum. Child and Adolescent Psychiatric Clinics of North America, 12, 1, pp. 107-122.

[12]Leef, J. (2005), A clinical intervention program for children with asperger syndrome and their parents: Promoting children's social skills and parents' selfconfidence. The Autism News Link, Spring, 14-15.

[13] Lowry, L. Parents as "Speech Therapists": What a new study shows, 2011, Retrieved from: http://www.hanen.org/HelpfulInfo/Articles/Parents-as--Speech-Therapists-What-a-New-Study-S.aspx (30 September 2014) 
[14] Matson, M.L., Mahan, S., \& Matson, J.L. (2009), Parent Training: A review of methods for children with autism spectrum disorder. Research in Autism Spectrum Disorder, 3, 868-875.

[15] McConachie, H., \& Diggle, T. (2007), Parent Implemented Early Intervention for young children with Autism Spectrum Disorder: A systematic review. Journal of Evaluation in Clinical Practice, 13, 120-129.

[16] Moroz, (2015), A. Exploring the factors related to parent involvement in the interventions of their children with Autism, Retrieved from: http://scholarworks.calstate.edu/bitstream/ha ndle/10211.3/139987/Anna\%20Kutsar\%20 Moroz\%20Thesis.pdf?sequence=1 (27 July 2016)

[17] The National Autistic Society. (2014). Social Skills in Young Children. Retrieved from: http://www.autism.org.uk/living-withautism/communicating-andinteracting/social-skills/social-skills-inyoung-children.aspx (11 November 2014)

[18] Pickard, K. E., Wainer, A. L., Bailey, K. M., \& Ingersoll, B. R. (2016), A mixed-method evaluation of the feasibility and acceptability of a telehealth-based parent-mediated intervention for children with autism spectrum disorder. Autism, 20, 7, pp. 845855.

[19]Poling, A., \& Edwards, T.L. Ethical Issues in Early Intervention. In Tarbox, J., Dixon, D.R., \& Sturmey, P. (ed.). Handbook of early intervention for Autism Spectrum Disorder: Research, policy, and practice.. New York: Springer Science+Business Media, 2014:177-206.

[20]Rocha, M.L., Schreibman, L., \& Stahmer, A.C. (2017), Effectiveness of training parents to teach joint attention in children with autism. Journal of Early Intervention, 29, 2, pp. 154-172.

[21]Rogers, S.J. (2000), Interventions that facilitate socialization in children with autism, Journal of Autism and Developmental Disorders, 30, 5, pp. 399409.
[22] Schertz, H.H., \& Odom, S.L. (2007), Promoting joint attention in toddlers with autism: A parent-mediated developmental model. Journal of Autism and Developmental Disorders, , 37, 8, pp. 15621575.

[23] Schreiber, C. (2010), Social skills interventions for children with highfunctioning Autism Spectrum Disorders. Journal of Positive Behavior Interventions, 13, 49-62.

[24] Shire, S.Y., et al. (2015), Parent's adoption of social communication intervention strategies: Families including children with Autism Spectrum Disorder who are minimally verbal. J Autism Dev disorder, , 45, 6, pp. 1712-1724.

[25] Steiner et al. (2012), Issues and theoritical constructs regarding parent education for Autism Spectrum Disorders. Journal of Autism Developmental Disorder, 42, 6.

[26] Stone, W., \& DiGeromino, T.F. (2014), Does my child have Autism?, in 100 Day Kit, For Newly Diagnosed Families of Young Children. Autism Speaks, Inc.

[27] Thomson, C.K., \& Jenkins, T. (2016), Training parents to promote communication and social behavior in children with Autism: The Son-Rise Program. Commun Disord Deaf Stud Hearing Aids, 4, 1, 1-7.

[28] Tonge, B., et al. (2014), A randomized group comparison controlled trial of preschoolers with autism: A parent education and skills training intervention for young children with autistic disorder. Autism, 18, 2, pp. 166-177.

[29] Wang, L. et al. (2013), Healthcare Service Use and Costs for Autism Spectrum Disorder, A Comparison Between Medicaid and Private Insurance, Journal of Autism Developmental Disorder, 43, 1057-1064.

[30] White, S., Koenig, K., \& Scahill, L. (2007), Social skills development in children with autism spectrum disorders: A review of intervention research. Journal of Autism and Developmental Disorders,. 37, 10, pp. 18581868. 